\title{
Análise fitossociológica de um remanescente de vegetação na microbacia do Córrego Criminoso (Bacia do Rio Taquari, Coxim, MS, Brasil): subsídios para a recomposição da vegetação
}

\author{
Adriana Maria Güntzel ${ }^{1,2}$, Nara Rocha Dias ${ }^{1}$, Charles Michel Coertjens ${ }^{1}$, \\ Geovane Cândido da Silva ${ }^{1}$ Evandro Alves Vieira ${ }^{1}$
}

Recebido em 14/06/2010. Aceito em 14/06/2011

\begin{abstract}
RESUMO
(Análise fitossociológica de um remanescente de vegetação na microbacia do Córrego Criminoso (Bacia do Rio Taquari, Coxim, MS, Brasil): subsídios para recomposição vegetal). O objetivo deste estudo foi realizar a análise florística e fitossociológica preliminar em um remanescente de vegetação na área de entorno do Córrego Criminoso, visando subsidiar futuros projetos de recomposição da vegetação. A área total do remanescente foi determinada com o auxílio de GPS e dos programas Pathfinder e Autocad. Amostragens de indivíduos com CAP maior ou igual a $20 \mathrm{~cm}$ foram realizadas em 20 parcelas de $300 \mathrm{~m}^{2}$ distribuídas na área. Foram encontradas 26 famílias botânicas contendo 36 gêneros e 49 espécies. A família Leguminosae foi a mais rica em espécies, seguida da família Annonaceae. A espécie Xylopia aromatica foi a mais freqüente, apresentando valores de IVI e IVC de 99,77 e 85,73, respectivamente. Observou-se que mais de $50 \%$ das espécies presentes na área são pioneiras ou secundárias, sendo cinco consideradas típicas de matas ciliares: Tapirira guianenses, Cecropia pachystachya, Terminalia argentea, Ocotea pulchellae e Luehea grandiflora. $\mathrm{O}$ remanescente de vegetação do entorno do Córrego Criminoso encontra-se fortemente degradado, necessitando de ações de manejo específicos nos fragmentos vegetados e nas áreas destituídas de vegetação, cujas recomendações são propostas.
\end{abstract}

Palavras-chave: área degradada, cerrado, florística, mata ciliar, nascentes

\begin{abstract}
(Phytosociological analysis of a vegetation remnant in the Córrego Criminoso Basin (Taquari River Basin, Coxim District, Mato Grosso do Sul, Brazil): data for vegetation recovery studies). The aim of this study was to complete a preliminary, floristic, phytosociological analyses of a vegetation remnant in the Criminoso Stream Basin, in order to provide data for future projects focusing on vegetation recovery. The total area of the remnant was determined using a GPS and the software Pathfinder and Autocad. Samples of individuals larger or equal to $20 \mathrm{~cm} \mathrm{CBH}$ were made in 20 quadrats that were $300 \mathrm{~m}^{2}$. Thirty-six genera and 49 species, within 26 botanical families, were found. The family Leguminosae was the richest in species, followed by the Annonaceae. Xylopia aromatica was the most frequent species, presenting values of IVI and IVC of 99.77 and 85.73 , respectively. More than $50 \%$ of the species present in the area are pioneer or secondary taxa, and five of these species are considered typical of riparian forests: Tapirira guianenses, Cecropia pachystachya, Terminalia argentea, Ocotea pulchellae and Luehea grandiflora. The vegetation remnant of the Criminoso Stream Basin is strongly degraded and needs specific management plans for the fragments that have and lack vegetation, whose recommendations are proposed.
\end{abstract}

Key words: disturbed land, cerrado, floristic, riparian vegetation, springs

1 Universidade Estadual de Mato Grosso do Sul, Unidade Universitária de Coxim, Coxim, MS, Brasil

2 Autor para correspondência: amguntzel@uems.br 


\section{Introdução}

Na bacia do Rio Taquari, as pressões resultantes da pecuária e da agricultura, atividades que representam o principal sustentáculo econômico da região, vêm se expandindo sobre áreas de cerrado, floresta e transições vegetacionais (Silva et al. 2005). A atividade agropecuária foi diagnosticada como sendo a principal responsável pela degradação dos corpos d'água da bacia, devido ao pisoteio da vegetação pelo gado que utiliza os cursos d'água para dessentação. Por esta razão, as áreas de vegetação que margeiam os rios, córregos e nascentes constituem uma das formações vegetais mais degradadas da região (Galdino \& Vieira 2005).

O córrego Criminoso está localizado próximo ao perímetro urbano do município de Coxim, sendo por muito tempo considerado um atrativo para o lazer pela exuberância de suas águas cristalinas, cercadas por uma vegetação nativa. Entretanto, este córrego tem sido explorado indiscriminadamente ao longo de sua história, onde fatores como o desmatamento, a pecuária e o uso inadequado do solo, estão entre os principais agentes responsáveis pela degradação da vegetação e de suas nascentes (Galdino \& Vieira 2005).

Por abranger várias propriedades rurais, alguns canais foram desviados do curso natural do córrego, bem como as nascentes foram represadas para o fornecimento de água ao gado. Além disso, a supressão da cobertura vegetal natural, substituindo-a por pastagens, associada ao fato desta região apresentar solos predominantemente arenosos, levou a área a um intenso processo de degradação, como conseqüência do assoreamento dos corpos d'água e da formação de voçorocas.

As iniciativas de restauração de áreas degradadas, principalmente em áreas ciliares, tiveram um aumento acentuado a partir dos anos 90, motivado pela conscientização da sociedade e pela exigência legal (Kageyama \& Gandara 2004). Com o intuito de promover a recuperação das Áreas de Preservação Permanente, a Lei de Política Agrícola - Lei $n^{\circ} 8171$, de 17 de janeiro de 1991, determina a recuperação gradual destas áreas, estabelecendo um período de 30 anos para a restauração da vegetação nativa nas áreas onde esta foi eliminada.

Por iniciativa da Promotoria de Meio Ambiente de Coxim, o projeto "Recuperação Ambiental do Córrego Criminoso" foi iniciado há quase dois anos, tendo como objetivo principal o enquadramento das propriedades que compõem esta microbacia, buscando atender à legislação ambiental, por meio da recuperação das Áreas de Preservação Permanente representadas pelas nascentes e vegetação de entorno do córrego (Rachid 2007).

Embora a recuperação de áreas degradadas tenha se caracterizado até recentemente pelo simples plantio de mudas com o objetivo principal de controlar a erosão, atualmente este processo adquiriu um caráter de área de conhecimento fundamentada em pesquisa científica, implicando em estudos detalhados de vários aspectos necessários ao planejamento e elaboração de propostas de recuperação, com destaque para caracterização da vegetação (Rodrigues \& Gandolfi 2004).

Estudos florísticos e fitossociológicos surgiram com a necessidade de obter dados sobre as comunidades vegetais dos diferentes biomas existentes e descrever sua composição, estrutura, distribuição e dinâmica das espécies (Felfili \& Venturoli 2000; Carvalho et al. 2001). Assim, a caracterização tanto do ambiente quanto da estrutura de populações de plantas é importante para fornecer informações sobre os fatores que influenciam os processos ecossistêmicos e a regeneração. Conhecer a flora e a estrutura comunitária da vegetação natural é importante para o desenvolvimento de modelos de conservação, manejo de áreas remanescentes e recuperação de áreas degradadas (Miranda-Melo et al. 2007).

Neste contexto, o objetivo deste estudo foi realizar uma análise florística e fitossociológica preliminar em um remanescente de vegetação no entorno das nascentes do Córrego Criminoso, visando subsidiar futuros projetos de recomposição da vegetação.

\section{Metodologia}

\section{Área de Estudo}

A microbacia do Córrego Criminoso localiza-se na Bacia Hidrográfica do Rio Taquari, entre as coordenadas, $18^{\circ} 27^{\prime} 49,9^{\prime \prime}$ e $18^{\circ} 29^{\prime} 21^{\prime \prime}$ de latitude Sul, e $54^{\circ} 43^{\prime} 56,7^{\prime \prime}$ e $54^{\circ} 45^{\prime} 13,9^{\prime \prime}$ de longitude Oeste. O córrego é um afluente da margem direita do Rio Taquari e localiza-se ao norte do estado de Mato Grosso do Sul, próximo ao perímetro urbano do município de Coxim, apresentando uma extensão aproximada de 5,5 km (Brasil 1990).

O clima da região é do tipo sub-úmido a semi-árido, caracterizando-se por dois meses de excedentes hídricos geralmente entre novembro a janeiro - e seis meses de deficiência hídrica - geralmente de maio a setembro. Integra a região do Primeiro Patamar da Borda Ocidental (região dos planaltos da borda ocidental da bacia do Paraná), no início da Serra do Pantanal, com altitudes médias na região urbana de cerca de $225 \mathrm{~m}$, apresentando como cobertura vegetal predominante o cerrado sentido restrito (Brasil/IBGE 1990). Contudo, grande parte do cerrado original foi transformado em pastagens, sendo preservados somente alguns remanescentes de mata ciliar e áreas de buritizais e veredas próximos a áreas alagadas em processo de recuperação. Possui quatro nascentes, bem próximas entre si, com evidentes sinais de perturbações antrópicas, especialmente pela supressão da cobertura vegetal natural e sua substituição por pastagens formadas por Brachiaria e pelo acesso do gado.

\section{Análise florística e fitossociológica}

A área total, de 28 ha e $6.305 \mathrm{~m}^{2}$, foi mensurada com o auxílio do GPS Pro Xrs, onde foram coletados os pontos do perímetro estudado. Após a coleta dos pontos GPS, os dados 
obtidos foram processados através do Programa Pathifinder e georreferenciadas no Sistema Geodésico Sad 69, possibilitando visualizar as coordenadas em UTM de cada parcela. Utilizou-se uma imagem de satélite para distribuir as vinte parcelas aleatoriamente sobre a área delimitada, por meio do programa Auto Cad 2006. Posteriormente utilizou-se o GPS (marca Garmin, modelo III Plus) para localizar as parcelas a campo, com $10 \mathrm{~m}$ de largura por $30 \mathrm{~m}$ de comprimento, totalizando uma área amostrada de $6.000 \mathrm{~m}^{2}$ (Figura 1).

Em cada parcela foram amostrados os indivíduos com o CAP (circunferência à altura do peito) igual ou maior que $20 \mathrm{~cm}$, feitas estimativas de altura do fuste (AF), altura total (AT) e tomada a medida da circunferência da base a $30 \mathrm{~cm}$ do solo. Os parâmetros fitossociológicos analisados foram: densidade absoluta (DA), densidade relativa (DR), freqüência absoluta (FA), freqüência relativa (FA), dominância absoluta (DoA), dominância relativa, índice de valor de cobertura (IVC) e índice de valor de importância (IVI). A identificação do material coletado foi realizada com o auxílio de bibliografia especializada, consulta a especialistas e comparação com exsicatas do herbário CG/MS da Universidade Federal de Mato Grosso do Sul.

\section{Resultados}

A análise resultou em 327 indivíduos amostrados (545 indivíduos/ha, cobrindo uma área de $12,78 \mathrm{~m}^{2} / \mathrm{ha}$ ), com altura do fuste variando entre $0,5 \mathrm{~m}$ e $8,5 \mathrm{~m}$ e altura total, entre $2,2 \mathrm{~m}$ e $11,0 \mathrm{~m}$, aproximadamente. Foram encontradas 26 famílias botânicas contendo 36 gêneros e 49 espécies. A família Leguminosae apresentou o maior número de espécies (9), seguida por Annonaceae e Vochysiaceae, ambas com três espécies cada. Três famílias foram representadas por duas espécies (Bignoniaceae, Bombacaceae e Moraceae) e 17 famílias foram representadas por uma única espécie (Tabela 1).

Quanto ao índice de valor de importância (IVI), a família Annonaceae obteve o maior percentual (34,5\%), seguida por Leguminosae $(18,45 \%)$ e Combretaceae $(14,52 \%)$, ou seja, apenas três famílias detiveram mais de $50 \%$ do índice. As

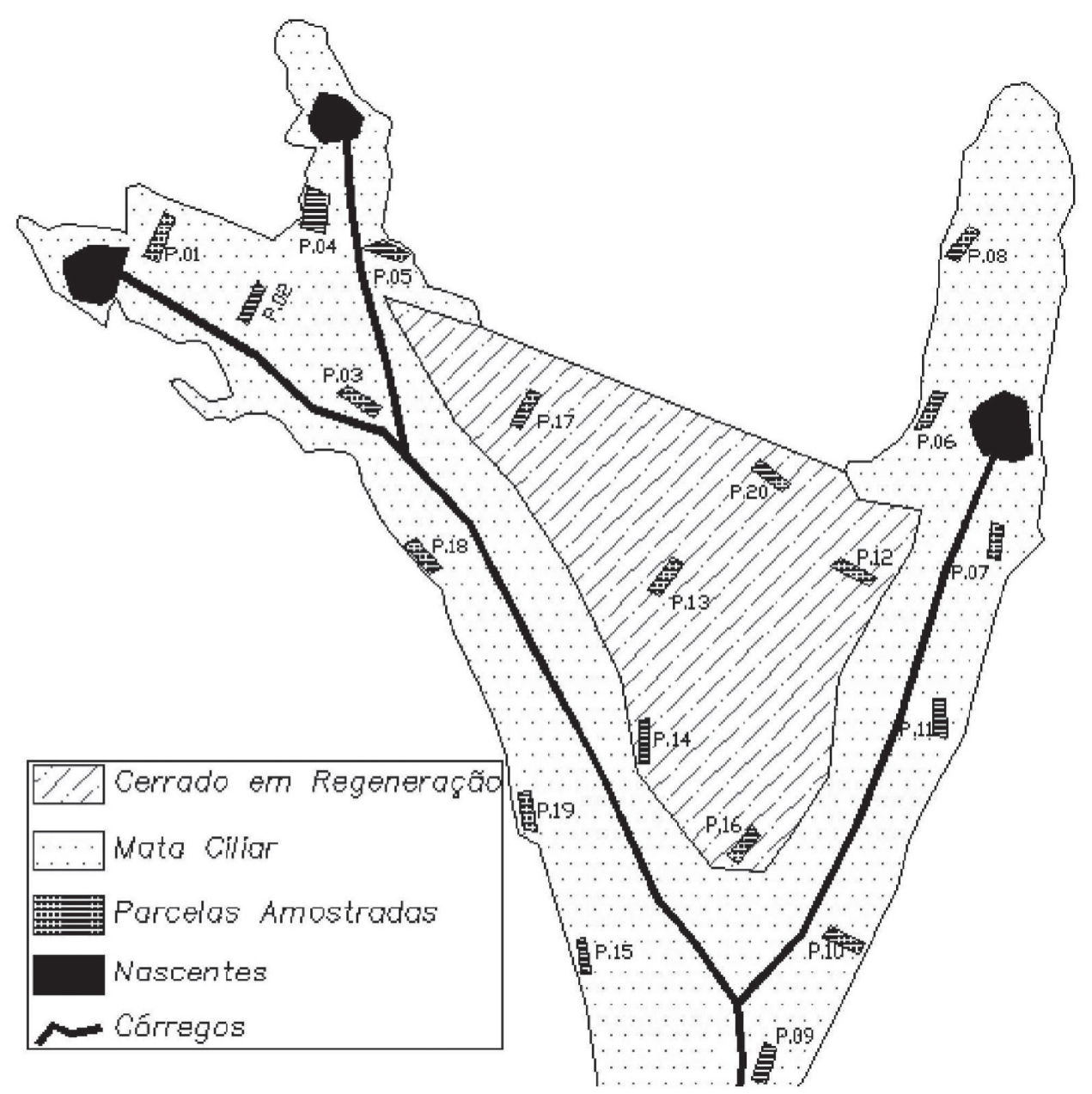

Figura 1. Localização das parcelas onde foi realizada a análise fitossociológica do remanescente de vegetação do entorno das nascentes do Córrego Criminoso, Coxim, MS. 
Análise fitossociológica de um remanescente de vegetação na microbacia do Córrego Criminoso (Bacia do Rio Taquari, Coxim, MS, Brasil)...

Tabela 1. Número de indivíduos, IVI e IVC das espécies amostradas no remanescente de vegetação do entorno das nascentes do Córrego Criminoso, Coxim, MS. N.I. - número de indivíduos; IVI - índice de valor de importância; IVC - índice de valor de cobertura; DA - densidade absoluta; DoA - dominância absoluta.

\begin{tabular}{|c|c|c|c|c|c|c|c|}
\hline Família & Espécie & Nome Vulgar & $\mathrm{NI}$ & $\mathrm{DA}$ & DoA & IVI & IVC \\
\hline Anacardiaceae & Tapirira guianensis Aubl. & Pombeiro & 35 & 58,33 & 1,87 & 35,02 & 25,37 \\
\hline \multirow[t]{3}{*}{ Annonaceae } & Annona cacans Warm. & Ariticum-cagão & 2 & 3,33 & 0,02 & 2,50 & 0,74 \\
\hline & Annona coriacea Mart. & Marolo & 1 & 1,67 & 0,01 & 1,25 & 0,37 \\
\hline & Xylopia aromatica (Lam.) Mart. & Pimenta-de-macaco & 136 & 226,67 & 5,64 & 99,77 & 85,73 \\
\hline Apocynaceae & Aspidosperma macrocarpon Mart. & Amargoso & 1 & 1,67 & 0,02 & 1,33 & 0,46 \\
\hline \multirow{2}{*}{ Bignoniaceae } & Jacaranda cuspidifolia Mart. & Jacarandá & 3 & 5,00 & 0,06 & 3,18 & 1,42 \\
\hline & Tabebuia sp. & Piúva & 2 & 3,33 & 0,08 & 2,98 & 1,23 \\
\hline Burseraceae & Protium heptaphyllum (Aubl.) March. & Mescla & 2 & 3,33 & 0,06 & 1,97 & 1,09 \\
\hline Urticaceae & Cecropia pachystachya Trec. & Embaúba & 6 & 10,00 & 0,21 & 6,96 & 3,45 \\
\hline Combretaceae & Terminalia argentea Mart. Et Succ. & Capitão-do-mato & 8 & 13,33 & 0,44 & 8,54 & 5,91 \\
\hline Dilleniaceae & Curatella americana $\mathrm{L}$. & Lixeira & 8 & 13,33 & 0,13 & 6,96 & 3,46 \\
\hline Erythroxylaceae & Erythroxylum anguifugum Mart. & Pimenteira & 1 & 1,67 & 0,06 & 1,69 & 0,81 \\
\hline Euphorbiaceae & Sapium longifolium Müll. Arg. & Pau-leiteiro & 1 & 1,67 & 0,03 & 1,41 & 0,54 \\
\hline Lauraceae & Ocotea pulchella Nees et Mart. & Canela-de-bugre & 1 & 1,67 & 0,01 & 1,29 & 0,41 \\
\hline \multirow[t]{2}{*}{ Leguminosae-Ceaesalpinoideae } & Dimorphandra mollis Benth. & Faveira & 5 & 8,33 & 0,03 & 2,61 & 1,73 \\
\hline & Copaifera martii Hayne & Guaranazinho & 7 & 11,67 & 0,18 & 5,33 & 3,57 \\
\hline \multirow[t]{2}{*}{ Leguminosae-Mimosoideae } & Stryphnodendron adstringens (Mart.)Cov. & Barbatimão & 1 & 1,67 & 0,03 & 1,45 & 0,58 \\
\hline & Albizia saman (Jacq.) F. Muell. & Farinha-seca & 24 & 40,00 & 1,36 & 25,04 & 18,02 \\
\hline \multirow[t]{5}{*}{ Leguminosae-Papilionoideae } & Vatairea macrocarpa (Benth.) Ducke & Pau-amargoso, Maleitoso & 3 & 5,00 & 0,09 & 4,29 & 1,66 \\
\hline & Dipteryx alata Vog. & Baru & 3 & 5,00 & 0,16 & 3,07 & 2,19 \\
\hline & Acosmium subelegans (Mohlenbr.) Yakovlev & Cascudo & 1 & 1,67 & 0,27 & 3,31 & 2,43 \\
\hline & Andira inermis (Sw.) H.B.K. & Morcego & 1 & 1,67 & 0,01 & 1,26 & 0,38 \\
\hline & Andira cuyabensis Benth. & Morcegueira & 4 & 6,67 & 0,13 & 4,01 & 2,25 \\
\hline Loganiaceae & Strychnos pseudoquina St.-Hil. & Quina-braba & 8 & 13,33 & 0,09 & 4,03 & 3,15 \\
\hline Malphighiaceae & Byrsonima orbignyana A. Juss. & Canjiqueira & 6 & 10,00 & 0,08 & 4,20 & 2,44 \\
\hline \multirow[t]{2}{*}{ Malvaceae } & Eriotheca gracilipes (K. Schum.) A. Rob. & Paina & 1 & 1,67 & 0,02 & 1,34 & 0,46 \\
\hline & Pseudobombax sp. & Paineira & 3 & 5,00 & 0,06 & 3,15 & 1,40 \\
\hline \multirow[t]{2}{*}{ Moraceae } & Ficus sp. & Figueira & 1 & 1,67 & 0,08 & 1,83 & 0,95 \\
\hline & Ficus insipida Willd. & Pau-do-brejo & 1 & 1,67 & 0,01 & 1,25 & 0,37 \\
\hline Myrtaceae & Gomidesia palustris (DC.) Legr. & Jacarezinho, Balsamin & 2 & 3,33 & 0,03 & 2,63 & 0,88 \\
\hline Oxalidaceae & Oxalis sp. & Azedinha & 1 & 1,67 & 0,01 & 1,28 & 0,40 \\
\hline Polygonaceae & Triplaris americana $\mathrm{L}$. & Formigueiro & 3 & 5,00 & 0,09 & 3,35 & 1,59 \\
\hline Rubiaceae & Alibertia edulis L.C. Rich. & Marmelada & 4 & 6,67 & 0,05 & 4,25 & 1,62 \\
\hline Sapindaceae & Magonia pubescens St. Hill. & Timbó & 2 & 3,33 & 0,12 & 3,30 & 1,55 \\
\hline Sapotaceae & Pouteria gardnerii (Mart. \& Miq.) Baehni & Peludinha & 1 & 1,67 & 0,02 & 1,37 & 0,49 \\
\hline Simaroubaceae & Simarouba versicolor St. Hil. & Perdiz & 1 & 1,67 & 0,02 & 1,37 & 0,49 \\
\hline Tiliaceae & Luehea grandiflora Mart. et. Zucc. & Açoita-cavalo & 2 & 3,33 & 0,04 & 1,78 & 0,90 \\
\hline \multirow[t]{3}{*}{ Vochysiaceae } & Vochysia divergens Pohl & Cambará & 10 & 16,67 & 0,38 & 8,67 & 6,04 \\
\hline & Vochysia tucanoro Pohl. & Cinzeiro & 1 & 1,67 & 0,06 & 1,69 & 0,81 \\
\hline & Qualea grandiflora Mart. & Pau-terra & 7 & 11,67 & 0,12 & 7,50 & 3,11 \\
\hline Não identificadas & & & 17 & 28,35 & 0,43 & 18,21 & 8,54 \\
\hline TOTAIS & & & 327 & 545,00 & 12,78 & - & - \\
\hline
\end{tabular}

espécies com maior índice de valor de importância (IVI) também apresentaram maior índice de valor de cobertura (IVC), sendo as três primeiras: Xylopia aromatica, Tapirira guianensis e Albizia saman. A Figura 2 indica as dez primeiras espécies que juntas somam $78,9 \%$ do índice de valor de cobertura.
As espécies Xylopia aromatica e Tapirira guianensis também foram as mais freqüentes na área amostrada, sendo que Xylopia aromatica ocorreu em $80 \%$ das parcelas, Tapirira guianensis ocorreu em 55\% e Albizia saman, em 40\% das parcelas amostradas. Ainda com relação à freqüência, observou-se que a grande maioria das espécies ocorreu 


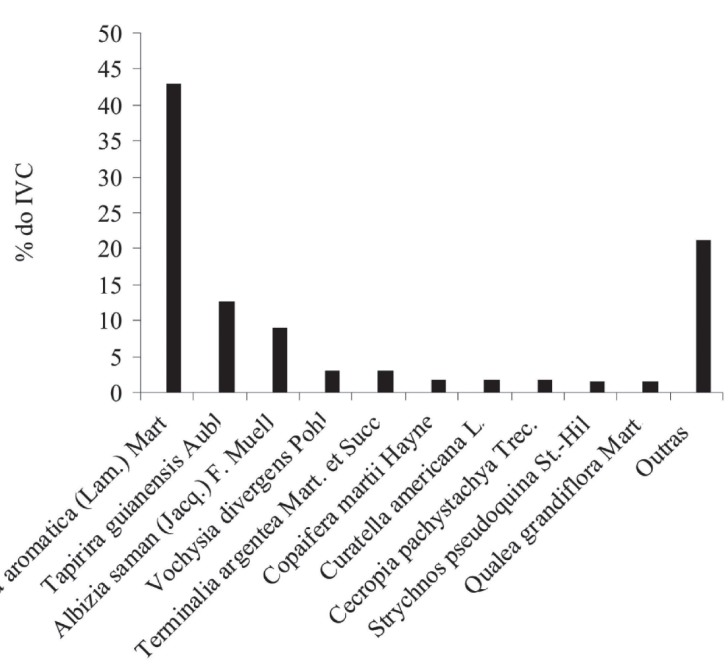

Figura 2. Dez primeiras espécies em IVC amostradas no fragmento de vegetação do entorno das nascentes do Córrego Criminoso, Coxim, MS.
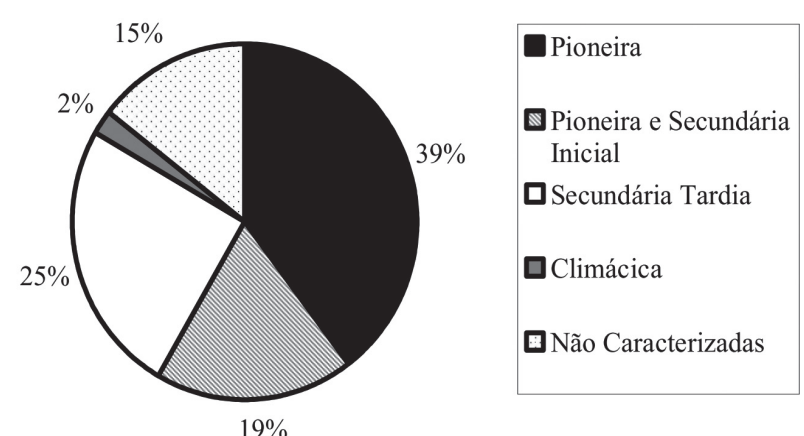

Figura 3. Porcentagem de indivíduos das espécies dos diferentes estádios sucessionais, no fragmento de vegetação do entorno das nascentes do Córrego Criminoso, Coxim, MS.

em uma única parcela, somando um total de 29 espécies. Ocorreram em duas parcelas um total de 11 espécies e em três parcelas, cinco espécies.

Com relação a cobertura, Xylopia aromatica ocupou uma área de 5,64 $\mathrm{m}^{2} /$ ha, Tapirira guianensis, uma área de 1,87 $\mathrm{m}^{2} /$ ha, seguidas da Albizia saman $\left(1,36 \mathrm{~m}^{2} / \mathrm{ha}\right)$ e Terminalia argentea $\left(0,44 \mathrm{~m}^{2} / \mathrm{ha}\right)$. Observou-se que mais de $50 \%$ dos indivíduos pertencem a espécies pioneiras, considerando aquelas que atuam tanto como pioneiras (39\%) quanto pioneiras-secundárias (19\%). Apenas 15\% do total de indivíduos não tiveram as espécies caracterizadas quanto ao estágio sucessional (Figura 3).

\section{Discussão}

$\mathrm{Na}$ área de estudo, foram observados fatores de degradação, como pisoteio de bovinos e eqüinos que utilizam as nascentes do Córrego Criminoso principalmente para a obtenção de água, impedindo assim o crescimento de es- pécies nativas em regeneração e intensificando os processos erosivos decorrentes da ausência da mata ciliar no entorno das nascentes. Não foram registradas espécies arbóreas exóticas, mas foi observada a presença de Brachiaria no extrato herbáceo, na área estudada, e monocultura de Eucalyptus em áreas adjacentes.

O perfil florístico do fragmento indicou que as famílias que apresentaram maior riqueza de espécies diferem daquelas observadas por Botrel et al. (2002) apud Campos et al. (2007) como as famílias com maior riqueza nas matas ciliares do Centro-Sul do Brasil (Myrtaceae, Lauraceae, Fabaceae e Euphorbiaceae).

Em 43 trabalhos realizados em matas ciliares do Brasil extra-amazônico, Rodrigues \& Nave (2001) verificaram que na maioria deles, em 35 trabalhos, ocorreram mais de 40 espécies, sugerindo que a área estudada no presente trabalho apresentou alta riqueza. Entretanto, entre as 40 espécies amostradas e identificadas, apenas cinco (Tapirira guianensis, Cecropia pachystachya, Terminalia argentea, Ocotea pulchellae e Luehea grandiflora), podem ser consideradas típicas de matas ciliares, pois são citadas em mais que $48 \%$ dos levantamentos florísticos e fitossociológicos de florestas ciliares do Brasil extra- amazônico. De acordo com a Resolução SMA de 21 de novembro de 2001, que fixa orientação para o reflorestamento heterogêneo de áreas ciliares degradadas (São Paulo 2001), as espécies Tapirira guianenses, Cecropia pachystachya, Terminalia argentea, Ocotea pulchellae e Luehea grandiflora são recomendadas para a revegetação dessas áreas no estado de São Paulo.

Com relação às demais espécies registradas no fragmento estudado, a maioria é citada na literatura apresentando altos valores de importância em áreas de cerrado sensu stricto, tais como: Qualea grandiflora, Curatella americana, Magonia pubescens, Dimorphandra mollis, Stryphnodendron adstringens, Protium heptaphyllum, Tabebuia sp (Balduíno et al. 2005); Vatairea macrocarpa (Felfili et al. 2002) e Qualea grandiflora (Saporetti et al. 2003).

Cardoso-Leite et al. (2004), em estudo sobre a fitossociologia e caracterização sucessional de um fragmento de mata ciliar em Rio Claro - SP, observaram a dominância de uma única espécie (Tapirira guianensis), a qual deteve $25 \%$ do IVC, atribuindo esta dominância a alterações na dinâmica natural da floresta, provavelmente advindas de ações antrópicas. No presente trabalho, a dominância de uma única espécie foi mais evidente, uma vez que a Xylopia aromatica atingiu $43 \%$ do IVC.

Apesar da grande riqueza de espécies encontradas no fragmento de vegetação, a alta dominância de Xylopia aromatica é um indicativo de expressiva alteração da vegetação da área do entorno das nascentes do Córrego Criminoso. Além disso, a maioria das espécies com valores altos de IVI e IVC na área estudada não são típicas de matas ciliares, e sim plantas características de cerrado, de início do estágio de sucessão, motivo pelo qual atingiram tais valores, indicando que o fragmento estudado sofreu perturbações recentes. 
De acordo com Lorenzi (1992), Xylopia aromatica é um planta semidecídua, heliófita e seletiva xerófita, encontrada geralmente em áreas perturbadas, como beira de estradas ou clareiras, sendo abundante em cerrado com alta luminosidade e apresentando alta capacidade de rebrotamento (Miranda-Melo et al. 2007), corroborando os resultados do presente estudo, uma vez que tais perturbações foram observadas na área.

A espécie Tapirira guianensis, que foi a segunda com o maior IVC, é abundante em solos argilosos, sendo pouco consumida pelo gado, rebrotando após cortes e fogo (Pott \& Pott 1994). No Pantanal, essa espécie é encontrada em margens de rios, áreas brejosas e margens de cordilheiras próximas ao campo inundável, sendo uma das espécies invasoras de pastagens nativas do Pantanal, disseminando-se em áreas de campo limpo, de vazantes e de baixadas, durante o período de inundação (Silva \& Rubio 2007). No presente estudo, essa espécie foi encontrada na área do entorno das nascentes do córrego, atualmente isolada do gado.

As outras espécies com valores altos de IVC foram Albizia saman, Terminalia argentea e Cecropia pachystachya. A espécie Albizia saman cresce melhor em solos úmidos e Vochysia divergens ocorre às vezes de forma monoespecífica, originando densas formações conhecidas como cambarazão, cuja ocorrência está associada a áreas periodicamente inundáveis, ocorrendo também em mata ciliar (Lorenzi 1992). Por outro lado, segundo o mesmo autor, Terminalia argentea é uma espécie decídua, heliófita, pioneira, característica do cerrado e da sua transição para a floresta semidecídua, ótima para plantios mistos e para recuperação de áreas de preservação permanente.

A ocorrência de muitas espécies com baixa freqüência pode estar relacionada com a heterogeneidade ambiental da área, onde é possível observar diferenças na declividade do terreno, no grau de umidade do solo e no nível de degradação, entre outros fatores, condicionando a ocorrência de um mosaico de vegetação com diferentes tolerâncias e adaptações às condições ambientais.

As causas da degradação da área estão relacionadas principalmente com a extração diferencial de madeira para fins econômicos e esportivos (árvores utilizadas na atividade de caça) e uso inadequado do solo (cultivo de Brachiaria e Eucalyptus) e da água (barragem das nascentes e desvio do curso do córrego), necessitando da elaboração de ações mais efetivas que permitam a continuidade e aceleração do processo de regeneração natural.

Entre as espécies com baixo IVI e IVC, as plantas indicadas para o adensamento de indivíduos são as pioneiras: Magonia pubecens, Luehea grandiflora, Annona coriacea, Stryphnodendron adstringens, Acosmium subelegans e Simarouba versicolor e as secundárias: Andira cuiabenses, Vatairea macrocarpa, Eriotheca gracilipes, Andira inermis, Ficus insipida, Pouteria gardnerii e Dipteryx alata, as quais são em sua maioria atrativas da fauna (Lorenzi 1992).

Para o enriquecimento de espécies sugerem-se as secundárias: indicadas para terrenos raramente inundados: Guarea guidonea (L.) Sleum., Nectandra rigida
Niss., Schizolobium parahybum (Vell.) Blaki. (Nappo et al. 1999), Anadenanthera macrocarpa Benth., Pterogyne nitens Tull., Machaerium spp Blak.; para terrenos inundados periodicamente: Genipa americana Linn. e Hyeronima alchorneoides Allem. (Nappo et al. 1999), Ormosia fastigiata Tull., e as climácicas: Aspidosperma ramiflorum Mull. ARG., Calophyllum brasiliense Camb., Dalbergia nigra (Vell)Alemão ex Benth. e Prunus myrtifolia (L.) URB. (Ferreira \& Dias 2004).

\section{Conclusões}

A partir dos resultados obtidos no presente estudo, pode-se concluir que o remanescente de vegetação do entorno do Córrego Criminoso encontra-se fortemente degradado, necessitando de ações de manejo específicos nos fragmentos vegetados e nas áreas destituídas de vegetação.

Como a área apresenta dominância de espécies pioneiras, recomenda-se que seja realizado o enriquecimento com espécies secundárias tardias e ou climácicas.

Sugere-se realizar o adensamento de indivíduos de algumas espécies secundárias, dando ênfase àquelas que são atrativas da fauna. Este adensamento deve ser feito através de mudas, de modo a acelerar o processo de recomposição da vegetação, visando a ampliação da área de preservação permanente por meio de introdução de espécies típicas de mata ciliar.

Nas áreas destituídas de vegetação, recomenda-se a implantação de consórcios de espécies pioneiras, secundárias e climácicas com o uso de mudas. Estas recomendações devem ser implementadas após o efetivo isolamento da área e do controle da vegetação de Brachiaria.

\section{Agradecimentos}

Agradecemos aos Professores Arnildo Pott e Ubirazilda Rezende pelo auxílio na identificação das espécies e ao Professor Luís Fernando Rolim de Almeida, pelas sugestões metodológicas.

\section{Referências Bibliográficas}

Balduino, A.P.C.; Souza, A.L.; Neto, J.A.A. M.; Silva, A.F. \& Júnior, M.C.S. 2005. Fitossociologia e análise comparativa da composição florística do cerrado da flora de Paraopeba - MG. Revista Árvore 29(1): 25-34.

Brasil. 1990. Mapa multi-referencial do Estado de Mato Grosso do Sul. Brasília, IBGE.

Cardoso-Leite, E.; Covre, T.B.; Ometto, R.G.; Cavalcanti, D.C. \& Pagani. M.I. 2004. Fitossociologia e caracterização sucessional de um fragmento de mata ciliar em Rio Claro/SP, como subsídio à recuperação da área. Revista do Instituto Florestal 16(1): 31-41.

Carvalho, A.R.; Romagnolo,M.B. \& Angelini, R. 2001. Diversidade florística entre matas de várzea da Bacia Amazônica e da planície de Rio Paraná. Ciências Biológicas e do Ambiente 3(1): 67-84.

Felfili, J.M. \& Venturoli, F. 2000. Tópicos em análise de vegetação. Comunicações técnicas florestais 2(2): 1-25.

Felfili, J.M.; Nogueira, P.E.; Júnior, M.C.S.; Marimon, B.S. \& Delitti, W.B.C. 2002. Composição florística e fitossociológica do cerrado sentido 
restrito no município de Água Boa - MT. Acta Botanica Brasilica 16(1): 103-112.

Ferreira, D.A.C. \& Dias, H.C.T. 2004. Situação atual da mata ciliar do ribeirão São Bartolomeu em Viçosa-MG. Revista Árvore 28(4): 617-623.

Galdino, S. \& Vieira, L.M. 2005. A Bacia do Rio Taquari e seus problemas ambientais e sócio-econômicos. In: Galdino, S.; Vieira, M.L.; Pellegrin, A.L. (Eds.). Impactos ambientais e sócio-econômicos na Bacia do Rio Taquari - Pantanal. Corumbá, Embrapa Pantanal.

Kageyama, P. \& Gandara, F.B. 2004. Recuperação de áreas ciliares. Pp. 249-269. In: Rodrigues, R.R.; Filho, L.F.H.; (Eds.). Matas ciliares: conservação e recuperação. São Paulo, Editora da Universidade de São Paulo, FAPESP.

Lorenzi, H. 1992. Árvores brasileiras: manual de identificação e cultivo de plantas arbóreas nativas do Brasil. Nova Odessa, Plantarum.

Miranda-Melo, A.A.; Martins, F.R. \& Santos, F.A.M. 2007. Estrutura populacional de Xylopia aromatica (Lam.) Mart. e Roupala montana Aubl. em fragmentos de cerrado no Estado de São Paulo. Revista Brasileira de Botânica 30(3): 501-507.

Nappo, M.E.; Gomes, L.J. \& Chaves, M.M.F. 1999. Reflorestamentos mistos com essências nativas para recomposição de matas ciliares. Boletim Agropecuário da Universidade Federal de Lavras 30: 1-31.
Pott, A. \& Pott, V.J. 1994. Plantas do Pantanal. Corumbá, EMBRAPA.

Rachid, A.L. 2007. Córrego Criminoso: um exemplo de sucesso. Disponível em <http://www.cointa.org.br> (Acesso em 23/03/2010).

Rodrigues, R.R. \& Gandolfi, S. 2004. Conceitos, tendências e ações para a recuperação de florestas ciliares. Pp. 235-247. In: Rodrigues, R.R.; Filho, L.F.H.; (Eds.). Matas ciliares: conservação e recuperação. São Paulo, Editora da Universidade de São Paulo, FAPESP.

Rodrigues, R.R. \& Nave, A.G. Heterogeneidade florística das matas ciliares. 2004. Pp. 45-71. In: Rodrigues, R.R.; Filho, L.F.H.; (Eds.). Matas ciliares: conservação e recuperação. São Paulo, Editora da Universidade de São Paulo, FAPESP.

São Paulo (Estado). 2001. Secretaria do Meio Ambiente. Resolução SMA 21, de 21-11-2001. Fixa orientação para o reflorestamento heterogêneo de áreas degradadas e dá providências correlatas. Diário Oficial do Estado de São Paulo 111: 221.

Saporetti, A.W.; Neto J.A.A.M. \& Almado, R. 2003. Fitossociologia de sub-bosque de cerrado em talhão de Eucalyptus grandis W. Hill ex Maiden no município de Despacho - MG. Revista Árvore 27(6): 905-910.

Silva, J.F. \& Rubio, T.C. 2007. Combretum lanceolatum como recurso alimentar para aves no Pantanal. Revista Brasileira de Ornitologia 15(3): 459-460. 